\title{
Transfer of Cleavage-Stage Embryos May Benefit Normal Responders With Low Rate of Morphologically Good Embryos Formation On Day 3: A Comparison Study
}

\section{Xiuliang Dai}

Nanjing Medical University Affiliated Changzhou Women and Children's Hospital: Changzhou Women and Children's Hospital

Xiyang Xia

Nanjing Medical University Affiliated Changzhou Women and Children's Hospital: Changzhou Women and Children's Hospital

\section{Tingting Gao}

Nanjing Medical University Affiliated Changzhou Women and Children's Hospital: Changzhou Women and Children's Hospital Chunmei Yu

Nanjing Medical University Affiliated Changzhou Women and Children's Hospital: Changzhou Women and Children's Hospital

\section{Fang Cao}

Nanjing Medical University Affiliated Changzhou Women and Children's Hospital: Changzhou Women and Children's Hospital

Tianfu Li

Nanjing Medical University Affiliated Changzhou Women and Children's Hospital: Changzhou Women and Children's Hospital

Lingjun Li

Nanjing Medical University Affiliated Changzhou Women and Children's Hospital: Changzhou Women and Children's Hospital

\section{Yufeng Wang}

Nanjing Medical University Affiliated Changzhou Women and Children's Hospital: Changzhou Women and Children's Hospital

\section{Li Chen ( $\square$ czrcchenli@126.com )}

Nanjing Medical University Affiliated Changzhou Women and Children's Hospital: Changzhou Women and Children's Hospital https://orcid.org/0000-0002-6478-6183

\section{Research}

Keywords: Embryonic quality, normal responders, rate of morphologically good day 3 embryos formation, day 3 embryos transfer, blastocysts transfer.

Posted Date: September 14th, 2021

DOI: https://doi.org/10.21203/rs.3.rs-860928/v1

License: @) (1) This work is licensed under a Creative Commons Attribution 4.0 International License. Read Full License 


\section{Abstract \\ Background}

Do morphologically good (MG) embryos from patients with high and low rate of MG embryos on day 3 (RMD3) show similar developmental potential (DP)?

\section{Methods}

This respective study finally included a total of 916 fresh cycles and related 1074 FET cycles from Jan 2017 to May 2020 in our reproductive center. Cycles with high RMD3 were defined as the $\mathrm{H}$ group, while cycles with low RMD3 were defined as the $\mathrm{L}$ group. The basic characteristics of patients and fresh cycles, blastulation rate, and clinical outcomes were compared between the $\mathrm{H}$ and $\mathrm{L}$ groups in either ET cycles with MG day 3 cleavage embryos (ETC group) or ET cycles with MG blastocysts (ETB group).

\section{Results}

The overall characteristics of patients and cycles were grossly comparable between the $\mathrm{H}$ and $\mathrm{L}$ groups either in ETC or ETB groups. In ETB group, useable blastocysts formation rate, implantation rate and live birth rate was significantly reduced in the $L$ group, compared to the $\mathrm{H}$ group; In ETC group, useable blastocysts formation rate was significantly reduced in the $\mathrm{L}$ group. However, implantation rate and livebirth rate was similar between the $L$ and $H$ groups.

\section{Conclusion}

The in vitro DP of MG day 3 embryos and in vivo DP of MG blastocysts were reduced significantly, while a similar in vivo DP of MG day 3 embryos was observed in patients with low RMD3 as compared to patients with high RMD3. It seems that direct transfer of day 3 MG embryos instead of extended culture may benefit patients with RMD3.

\section{Introduction}

In vitro fertilization/embryo transfer (IVF/ET) technology is the most effective way for treatment of infertility. Many factors may influence the success of IVF, such as female age, duration of sub-fertility, bFSH and number of oocytes (1). Among them, the number of oocytes is widely accepted as a maker indicating prognosis in the clinicians and patients. For a patient, more oocytes obtained may represent more available embryos for transfer, and more chance of having pregnancy within 1 oocyte retrieval cycle $(2,3)$. Previous studies have already showed that the live birth rate is strong associated with the number of oocytes (4). Ji et.al has demonstrated that for patient ( = >160ocytes), the cumulative live birth rate per cycle is the highest among groups(5). Therefore the number of eggs takes the quantitative advantage.

It is known that day 3 cleavage embryos and blastocysts are the most used for transfer.

Morphological score of embryonic quality (including cleavage embryos and blastocysts) is still the most used in evaluating the quality of embryos in reproductive center worldwide, although other embryonic screen methods are emerging (6-10). According to the morphological grading system, useable embryos include morphologically good (MG) and morphologically non-good (MNG) embryos. For day 3 cleavage embryo, MG embryos refers to grade I and grade II embryos, while MNG embryo refers to grade III embryo. For blastocyst, blastocyst with A or B score of the inner cell mass and the trophectoderm is defined as MG blastocyst, while blastocyst with a $\mathrm{C}$ score of either the inner cell mass or the trophectoderm and a A or B score of their counterpart is defined as MNG blastocyst. Actually, MG embryos determine the success of IVF treatment in a large extent (11, 12). 
In clinical practice, the number of eggs is not always consistent with the MG embryos on day 3 . For some patients, although they may have a satisfying number of normally fertilized oocytes, the in vitro development of fertilized oocytes is poor, resulting in relatively limited available MG embryos on day 3. It is known that morphological score roughly evaluate the quality of embryos. Embryos with similar morphological score may have differential quality. A best example of this is the differential quality of MG embryos from young and aged women(13). The number of MG embryos needed for a successful live birth is quite different between young and aged women(14-16). Therefore, it should not be taken it for granted that embryos with similar morphological score may have similar quality. Here, we asked whether the remaining MG embryos from patients with low rate of MG embryos formation on day 3 (RMD3) show similar quality as MG embryos from patients with high RMD3. In another word, it is obvious that patients with low RMD3 have limited MG embryos, it remains unclear that whether they have similar embryonic quality, compared to patients with high RMD3. It is known that quality may be as the same important as quantity in determining the success of IVF/ICSI cycles $(17,18)$.To our knowledge, no data were published to illustrate this issue.

Having insight into this issue is clinically important. First, it may help patients and clinicians to build suitable expectation on the chance of success of transfer of MG embryos for patients with low RMD3. Second, it may help clinicians to offer better consultant service to patients with LRTD3.Third it may help clinicians to develop more suitable and scientific strategy for the infertility treatment for patients with low RMD3, such as what stage of embryos should be transferred that may benefit patients with low RMD3.

To address this issue, we respectively analyzed the data generated from Jan 2017 to May 2020 in our reproductive center. Oocyte retrieval cycles were ranked by RMD3, cycles in the bottom 25th percentile was defined as the $L$ group, while cycles in the top 25th percentile was defined as the H group. Finally, a total of 916 fresh cycles and related 1074 FET cycles were included in the present study. The basic characteristics of patients and cycles, blastocyst formation rate, and clinical outcomes were compared between the $\mathrm{H}$ and $\mathrm{L}$ groups in either ET cycles with MG day 3 cleavage embryos (ETC group) or ET cycles with MG blastocysts (ETB group) separately.

\section{Methods}

\section{Study design}

A retrospective study was conducted in the reproductive medical center of the Nanjing Medical University Affiliated Changzhou Maternal and Child Health Care Hospital. Data generated from 908 patients who contributed a total of 916 fresh cycles and 1074 ET cycles (from Jan 2017 to May 2020) were finally included for analysis. Actually, 1798 couples with 1851 fresh cycles were initially included for analysis. According to RMD3, cycles in the top 25th percentile were defined as the $\mathrm{H}$ group, while cycles in the bottom 25th were defined as the L group. Comparisons including the basic characteristics of patients and cycles, blastulation rate, and clinical outcomes were compared between the $\mathrm{H}$ and $\mathrm{L}$ groups in ETB or ETC group.

\section{Inclusion/exclusion criteria}
a) Excluding the cycles with $2 \mathrm{PN}-z y g o t e s<5$.
b) Excluding the cycles of PESA/TESA/late ICSI.
c) Male or female with a history of cancer or having chromosomal abnormality, or female having a diagnosis of recurrent spontaneous abortion.
d) Excluding cycles without expanding culture of day 3 embryos.
e) For ET cycles, transfer with sole MG embryos (including MG blastocysts or day 3 embryos) were included for analysis. Transfer with MNG embryos were excluded for analysis.

\section{Embryo culture procedures}

The ovarian stimulation protocols including long protocol, antagonist protocol, PPOS protocol and mini-stimulation protocol were conducted as previously described(14). Thirty-six hours later, oocyte retrieval was performed after the trigger.Conventional IVF or ICSI method was used for insemination. Eighteen hours after insemination, zygotes with 2 pronuclei were defined as normal fertilization. The normal fertilization zygotes were transferred into G1 plus medium (Vitrolife, Sweden) for further culture. 
On day 3, the morphological score of the embryos was performed according to an established grading system(19). In the present study, the MG day 3 embryos refer to Grade I and II embryos, while MNG day 3 embryos refer to Grade III embryos. Grade IV embryos was abandoned. MG or MNG day 3 embryos were either frozen by vitrification method, or for transfer, or for expanding culture. For expanding culture, day 3 embryos were transferred into drops of G2-plus medium (Vitrolife, Sweden).On day 5 or 6 , the embryos were evaluated by morphological score. Blastocyst with $C$ or less $C$ score of the inner cell mass and the trophectoderm was abandoned; blastocyst with A or B score of the inner cell mass and the trophectoderm was defined as the MG blastocyst; blastocyst with a C score of either the inner cell mass or the trophectoderm and a A or B score of another (the trophectodermor the inner cell mass) was defined as the MNG blastocyst. The usable blastocysts represented the MG or MNG blastocysts. The usable blastocysts were frozen by vitrification or transferred into the uterine cavity. Furthermore,morphological evaluation of embryos in our reproductive center was performed by Dr. Yufeng Wang, who has more than ten years of work experience as an embryologist.

\section{Statistical analysis}

All analyses were performed using SPSS software (Version 21, IBM). For a comparison of the constituent ratio, the chi-square test was employed; for a comparison of the continuous data, the data were first examined by the Normality and lognormality test. If data fitting the pattern of normally distributed, student $t$ test was employed, if not, the Mann-Whitney $U$ test was employed.For analysis of pregnancy and live birth,logistic regression analyses were used. Logistical regression analysis of clinical outcomes of day 3 cleavage embryos or blastocysts transfer, were adjusted for age of male or female, fresh or frozen ET cycles, number of embryos transferred, female BMI, sperm DFI to estimate the odds ratio(OR) with a $95 \% \mathrm{Cl}$ among the study groups.

\section{Results}

\section{The flow chart of the present study}

A total of 3905 fresh cycles/3090 couples from Jan 2017 to May 2020 in the reproductive medical center of Nanjing Medical University Affiliated Changzhou Maternal and Child Health Care Hospital was initially included in the present study (Fig. 1). For controlling the fluctuation of RMD3, fresh cycles with 2 PN-zygotes $<5$ were excluded. Cycles of PESA/TESA/late ICSI, male or female with a history of cancer or having chromosomal abnormality, or female having a diagnosis of recurrent spontaneous abortion were further excluded. Furthermore, For collecting data from extented culture, fresh cycles without blastocysts culture were excluded. After these, a total of 1851 fresh cycles/1798 couples was left (Fig. 1). Then we rank fresh cycles according to RMD3. The cycles in the bottom 25th percentile were defined as the $L$ group, while the cycles in the top 25th percentile were defined as the $\mathrm{H}$ group. A total of 463 fresh cycles was included in the $\mathrm{L}$ group while a total of 504 fresh cycles was included in the $\mathrm{H}$ group (Fig. 1). In the L group, 463 fresh cycles contributed 275 day 3 embryo transfer cycles and 282 blastocysts transfer cycles; in the $\mathrm{H}$ group, 504 fresh cycles contributed 189 day 3 embryo transfer cycles and 482 blastocyst transfer cycles (Fig. 1). Given the uneven distribution of ET cycles with MNG embryos between the $\mathrm{H}$ and $\mathrm{L}$ groups and a quite small fracture of ET cycles with MNG embryos in the H group, therefore, we excluded the ET cycles with MNG embryos for analysis. Finally, a total of 259 MG day 3 transfer cycles (from 242 fresh cycles) and 200 MG blastocysts transfer cycles (from 162 fresh cycles) was presented in the L group, while a total of 189 MG day 3 transfer cycles ( 169 fresh cycles) and 426 MG blastocysts transfer cycles (from 343 fresh cycles) was presented in the H group (Fig. 1). Data from these ET cycles were used for analysis of clinical outcomes of transfer of the MG blastocysts or day 3 embryos. As shown in Fig. 2, 195 vs.108 fresh cycles had MG day 3 embryo transfer only, 122 vs. 289 fresh cycles had MG blastocyst transfer only, and 47 vs. 54 fresh cycles had both MG day 3 embryo and blastocyst transfer in the L vs. H group (Fig. 2). Therefore, patients having ETC and patients having ETB represented relatively separate population in the $\mathrm{L}$ and $\mathrm{H}$ groups. Therefore parameters of couples, cycles and in vitro embryonic development were compared between the $\mathrm{L}$ and $\mathrm{H}$ groups in ETC or ETB group separately (Fig. 1).

\section{Baseline characteristics of couples, parameters of cycles and in vitro embryo development}


Baseline characteristics of couples or cycles were comparable between the $\mathrm{H}$ and $\mathrm{L}$ groups in ETC or ETB, including the percentage of primary infertility, duration of infertility, primary diagnosis, age of males and females, the level of bFSH or AMH in females, AFC, BMI of males and females, semen DFI, the distribution of ovulation protocols, total dose of $\mathrm{Gn}$ and duration of Gn treatment (Table 1). E2 on the HCG day, oocytes retrieved, MIl oocytes and 2-PN zygotes were lower significantly while rate of 2PN zygotes was higher significantly in the $\mathrm{H}$ group than those in the L group in the ETC group (Table 1). Rate of MII oocytes were similar in the L and H groups in the ETC group. E2 on the HCG day, oocytes retrieved, MIl oocytes and 2-PN zygotes were similar in the $\mathrm{H}$ and $\mathrm{L}$ groups in the ETB group (Table 1). Rate of MIl oocytes and rate of 2PN zygotes were significantly higher in the $\mathrm{H}$ groups than those in the $\mathrm{L}$ group in the ETB group (Table 1). Useable day 3 embryos, rate of usable day 3 embryos, MG day 3 embryos, rate of MG day 3 embryos, useable blastocysts and rate of useable blastocysts (from MG day 3 embryos or from MNG day 3 embryos) were significantly lower in the $L$ group than those in the $H$ group in either ETC or ETB group (Table 1).

\section{Table 1 Baseline characteristics of couples, parameters of cycles and in vitro embryo development}

Data are presented as the median [the first quartile, the third quartile] or count (percentage).

DFI: DNA fragmentation index; Gn: gonadotropin; AFC antral follicle count; MG: morphologically good; MNG:morphologically non-good; ETC: ET cycles with MG day 3 cleavage embryos; ETB: ET cycles with MG blastocysts

*Semen was analyzed by CASA 2 weeks before oocyte retrieval.

\section{Characteristics and clinical outcomes of ETB}

More number of MG blastocysts per ET cycle and decreased rate of ET cycles with single blastocyst were observed in the $\mathrm{H}$ group (Table 2). The rate of fresh cycles in the $L$ or $\mathrm{H}$ groups was similar (Table 2). Rate of Cycles with day 5 blastocysts was significantly higher, while rate of cycles with day 6 blastocysts was significantly lower in the $\mathrm{H}$ group than those in the $\mathrm{L}$ group (Table 2). However,the rate of clinical pregnancy, live birth, implantation and live birth per embryo was significantly lower in the $\mathrm{L}$ group than in the $\mathrm{H}$ group (Table 2). Abortion rate was similar in the $\mathrm{L}$ and $\mathrm{H}$ groups (Table 2). 
ETC

ETB

\begin{tabular}{lllllll} 
& $\mathrm{L}$ & $\mathrm{H}$ & $\mathrm{p}$ & $\mathrm{L}$ & $\mathrm{H}$ & $\mathrm{p}$ \\
\hline Cycles(n) & 242 & 162 & $/$ & 169 & 343 & $/$ \\
\hline Couples (n) & 235 & 162 & $/$ & 168 & 343 & $/$ \\
\hline $\begin{array}{l}\text { Primary } \\
\text { infertility (\%) }\end{array}$ & $137(56.61)$ & $89(54.94)$ & 0.7399 & $92(54.44)$ & $193 / 343(56.27$ & 0.695 \\
\hline $\begin{array}{l}\text { Infertility } \\
\text { duration } \\
\text { (years) }\end{array}$ & $3[2,5]$ & $3[2,5]$ & 0.3449 & $3[2,5]$ & $3[2,4]$ & 0.2913 \\
\hline
\end{tabular}

Age (years)

\begin{tabular}{|c|c|c|c|c|c|c|}
\hline Female & $30[28,33]$ & $30[28,33.25]$ & 0.4795 & $30[28,33]$ & $30[28,33]$ & 0.5762 \\
\hline Male & $31[29,35]$ & $30[28,35]$ & 0.0556 & $32[29,35]$ & $31[29,34]$ & 0.0602 \\
\hline \multicolumn{7}{|l|}{$\mathrm{BMI}(\mathrm{kg} / \mathrm{m} 2)$} \\
\hline Female & $\begin{array}{l}22.10[20.20, \\
24.75]\end{array}$ & $22.4[20.5,25.2]$ & 0.3971 & $21.85[19.9,24.3]$ & $22[20,24.9]$ & 0.3937 \\
\hline Male & $24.4[22.3,27.4]$ & $24.7[22.4,27.23]$ & 0.9434 & $24.2[21.53,26.78]$ & $24.55[22,27.18]$ & 0.2003 \\
\hline Semen DFI & $\begin{array}{l}10.61 \\
{[7.213,16.46]}\end{array}$ & $\begin{array}{l}10.30 \\
{[6.848,14.99]}\end{array}$ & 0.5187 & $9.97[6.16,15.11]$ & $10.41[6.7,16.4]$ & 0.2357 \\
\hline AFC & $10[7,14]$ & $10[8,14]$ & 0.8166 & $11[8,14]$ & $11.5[8,16]$ & 0.6474 \\
\hline \multicolumn{7}{|l|}{$\begin{array}{l}\text { Primary } \\
\text { diagnosis }\end{array}$} \\
\hline Tubal & $110(45.45)$ & $84(51.85)$ & 0.2072 & $84(49.70)$ & $185(53.94)$ & 0.3672 \\
\hline $\begin{array}{l}\text { Ovulation } \\
\text { defect }\end{array}$ & $28(11.57)$ & $23(14.20)$ & 0.4358 & 25 (14.79) & 49 (14.29) & 0.878 \\
\hline Male factor & $40(16.53)$ & $17(10.49)$ & 0.0877 & $20(11.83)$ & 39 (11.37) & 0.8771 \\
\hline others & $64(26.45)$ & $38(23.46)$ & 0.4979 & $40(23.67)$ & $70(20.41)$ & 0.3983 \\
\hline
\end{tabular}

Female

hormonal

level

$\begin{array}{llllll}\text { Basal FSH, } \quad 6.43[5.61,7.50] & 6.615[5.563,7.88] & 0.5462 & 5.96[5.13,7.12] & 6.17[5.263,7.452] & 0.1582\end{array}$ IU/I

$\mathrm{AMH}, \mathrm{ng} / \mathrm{ml} \quad 3.31[2.203,5.568] \quad 3.17[1.968,5.363] \quad 0.5555 \quad 4.07[2.765,6.5] \quad 4.43[1.848,6.908] \quad 0.5056$

GnRH

analogues(\%)

\begin{tabular}{lllllll} 
Agonist & $177(73.14)$ & $121(74.69)$ & 0.7284 & $140(84.02)$ & $280(81.63)$ & 0.5039 \\
\hline Antagonist & $40(16.53)$ & $28(17.28)$ & 0.8424 & $27(15.98)$ & $60(17.49)$ & 0.6675 \\
\hline Others & $25(10.33)$ & $13(8.03)$ & 0.095 & $0(0)$ & $3(0.87)$ & 0.2227 \\
\hline $\begin{array}{l}\text { Total dose of } \\
\text { Gn (IU) }\end{array}$ & $1706[1263,2400]$ & $1931[1322,2400]$ & 0.3312 & $1500[1075,2100]$ & $1425[1100,2138]$ & 0.8374 \\
$\begin{array}{l}\text { Duration of } \\
\text { Gn treatment } \\
\text { (days) }\end{array}$ & $9[8,10]$ & $9[8,10]$ & 0.5967 & $9[8,10]$ & $9[8,10]$ & 0.7377 \\
\hline E2 on the & $3009[2222,4244]$ & $2695[1878,3912]$ & 0.0157 & $3705[2606,5233]$ & $4007[2640,5282]$ & 0.7573
\end{tabular}




\begin{tabular}{|c|c|c|c|c|c|c|}
\hline $\begin{array}{l}\text { Oocytes } \\
\text { retrieved }\end{array}$ & $11[9,13]$ & $9[7,11]$ & $<0.0001$ & $12[10,16]$ & $13[10,15]$ & 0.616 \\
\hline Mll oocytes & $10[8,12]$ & $9[7,11]$ & $<0.0001$ & $12[9,15]$ & $12[9,14]$ & 0.7644 \\
\hline $\begin{array}{l}\text { Rate of MII } \\
\text { oocytes }\end{array}$ & $\begin{array}{l}2582 / 2759 \\
(93.58)\end{array}$ & $\begin{array}{l}1476 / 1565 \\
(94.31)\end{array}$ & 0.338 & $\begin{array}{l}2107 / 2244 \\
(93.89)\end{array}$ & $\begin{array}{l}4143 / 4354 \\
(95.15)\end{array}$ & 0.0302 \\
\hline 2PN zygotes & $8[6,10]$ & $7[6,9]$ & 0.0002 & $10[7,12]$ & $10[7,12]$ & 0.7305 \\
\hline $\begin{array}{l}\text { Rate of 2PN } \\
\text { zygotes }\end{array}$ & $2065 / 2759(74.85)$ & $\begin{array}{l}1214 / 1565 \\
(77.57)\end{array}$ & 0.0442 & $\begin{array}{l}1705 / 2244 \\
(75.98)\end{array}$ & $\begin{array}{l}3418 / 4354 \\
(78.50)\end{array}$ & 0.0198 \\
\hline $\begin{array}{l}\text { Usable day } 3 \\
\text { embryos }\end{array}$ & $7[5,8]$ & $7[6,9]$ & 0.0471 & $8[6,10]$ & $10[7,11]$ & $<0.0001$ \\
\hline $\begin{array}{l}\text { Rate of } \\
\text { usable day } 3 \\
\text { embryos }\end{array}$ & $1675 / 2065(81.11)$ & 1199/1214(98.76) & $<0.0001$ & 1437/1705(84.28) & $3343 / 3418(97.81)$ & $<0.0001$ \\
\hline $\begin{array}{l}\text { MG day } 3 \\
\text { embryos }\end{array}$ & $3[2,4]$ & $7[6,9]$ & $<0.0001$ & $4[3,6]$ & $9[7,11]$ & $<0.0001$ \\
\hline $\begin{array}{l}\text { MG day } 3 \\
\text { embryos } \\
\text { from 2PN (\%) }\end{array}$ & $836 / 2065$ (40.48) & $\begin{array}{l}1183 / 1214 \\
(97.45)\end{array}$ & $<0.0001$ & 825/1705 (48.39) & $\begin{array}{l}3266 / 3418 \\
(95.55)\end{array}$ & $<0.0001$ \\
\hline $\begin{array}{l}\text { Usable } \\
\text { blastocysts }\end{array}$ & $1[0,2]$ & $3[2,4]$ & $<0.0001$ & $3[2,4]$ & $5[4,7]$ & $<0.0001$ \\
\hline \multicolumn{7}{|l|}{$\begin{array}{l}\text { Blastulation } \\
\text { rate }\end{array}$} \\
\hline $\begin{array}{l}\text { From MG } \\
\text { embryos (\%) }\end{array}$ & 171/321 (53.27) & $476 / 769$ (61.90) & 0.0082 & $401 / 585$ (68.58) & $\begin{array}{l}1910 / 2630 \\
(72.62)\end{array}$ & 0.0473 \\
\hline $\begin{array}{l}\text { From MNG } \\
\text { embryos (\%) }\end{array}$ & 179/818(21.88) & $5 / 30(16.67)$ & 0.496 & 177/651(27.19) & $33 / 113(29.2)$ & 0.6579 \\
\hline
\end{tabular}


Table 2

Characteristics and clinical outcomes of ETB

\begin{tabular}{|c|c|c|c|}
\hline & $\mathbf{L}$ & $\mathbf{H}$ & $\mathbf{P}$ \\
\hline ET cycles & 200 & 426 & \\
\hline Fresh & $28(14)$ & $40(9.39)$ & 0.0839 \\
\hline Frozen & $172(86)$ & $386(90.61)$ & 0.0839 \\
\hline \multicolumn{4}{|l|}{ Days of blastocysts } \\
\hline Day 5 & $114(57 \%)$ & $342(80 \%)$ & \\
\hline Day $5+$ day 6 & $10(5 \%)$ & $13(3 \%)$ & \\
\hline Day 6 & $76(38 \%)$ & $71(17 \%)$ & \\
\hline Embryos /transfer & $1.27 \pm 0.45$ & $1.47 \pm 0.50$ & $<0.0001$ \\
\hline Single embryo transfer cycles (\%) & $146(73.00)$ & $225(52.82)$ & $<0.0001$ \\
\hline Pregnancy rate (\%) & $118(59.00)$ & $318(74.65)$ & $<0.0001$ \\
\hline Abortion rate (\%) & $19(16.10)$ & $47(14.78)$ & 0.7322 \\
\hline Live birth rate (\%) & $98(49.00)$ & $271(63.62)$ & $<0.0001$ \\
\hline Implantation rate (\%) & $137 / 254(53.94)$ & $406 / 627(64.75)$ & 0.0028 \\
\hline Live birth per embryo (\%) & $114 / 254(44.88)$ & $341 / 627$ (54.39) & 0.0106 \\
\hline \multicolumn{4}{|c|}{ Data are presented as the median [the first quartile, the third quartile] or count (percentage) } \\
\hline \multicolumn{4}{|c|}{ ETB:Embryo transfer with morphologically good blastocysts } \\
\hline
\end{tabular}

\section{Factors affecting the clinical outcomes of ETB}

Binary logistic regression analysis showed that number of embryos transferred and female age significantly affected clinical pregnancy and live birth (Table 3). The days of MG blastocysts significantly affected abortion (Table 3). After controlling factor including female or male age, number of embryos transferred, female BMI, semen DFI and days of blastocyst, we found MG blastocysts from the $L$ group showed decreased chance of implantation or live birth, compared to the $\mathrm{H}$ group (Table 3 ). 
Table 3

Association between factors and clinical outcomes in ETB

\begin{tabular}{|c|c|c|c|c|c|c|}
\hline & \multicolumn{2}{|c|}{ Clinical pregnancy } & \multicolumn{2}{|l|}{ Live birth } & \multicolumn{2}{|l|}{ abortion } \\
\hline & OR (95\% CL) & $\mathrm{p}$ & OR (95\% CL) & $\mathrm{p}$ & OR (95\% CL) & $\mathrm{p}$ \\
\hline \multicolumn{7}{|l|}{ ET cycles } \\
\hline Day 5 blastocysts & 1 (ref) & & 1 (ref) & & 1 (ref) & \\
\hline Day $5+$ day 6 blastocysts & $\begin{array}{l}0.461(0.166- \\
1.285)\end{array}$ & 0.139 & $\begin{array}{l}0.483(0.184- \\
1.269)\end{array}$ & 0.140 & $\begin{array}{l}1.442(0.292- \\
7.127)\end{array}$ & 0.653 \\
\hline Day 6 blastocysts & $\begin{array}{l}0.876(0.557- \\
1.379)\end{array}$ & 0.568 & $\begin{array}{l}0.645(0.421- \\
0.989)\end{array}$ & 0.045 & $\begin{array}{l}2.095(1.118- \\
3.927)\end{array}$ & 0.021 \\
\hline $\begin{array}{l}\text { Number of embryos } \\
\text { transferred }\end{array}$ & $\begin{array}{l}2.299(1.533- \\
3.447)\end{array}$ & 0.000 & $\begin{array}{l}2.062(1.434- \\
2.965)\end{array}$ & 0.000 & $\begin{array}{l}0.727(0.414- \\
1.274)\end{array}$ & 0.265 \\
\hline Semen DFI & $\begin{array}{l}0.979(0.956- \\
1.002)\end{array}$ & 0.069 & $\begin{array}{l}0.988(0.966- \\
1.01)\end{array}$ & 0.268 & $\begin{array}{l}0.990(0.954- \\
1.027)\end{array}$ & 0.581 \\
\hline Female BMI & $\begin{array}{l}0.979(0.928- \\
1.032)\end{array}$ & 0.422 & $\begin{array}{l}0.971(0.925- \\
1.020)\end{array}$ & 0.245 & $\begin{array}{l}1.042(0.965- \\
1.125)\end{array}$ & 0.293 \\
\hline Female age & $\begin{array}{l}0.905(0.847- \\
0.966)\end{array}$ & 0.003 & $\begin{array}{l}0.916(0.861- \\
0.975)\end{array}$ & 0.006 & $\begin{array}{l}1.026(0.928- \\
1.134)\end{array}$ & 0.616 \\
\hline Male age & $\begin{array}{l}1.002(0.952- \\
1.054)\end{array}$ & 0.939 & $\begin{array}{l}0.996(0.949- \\
1.045)\end{array}$ & 0.857 & $\begin{array}{l}1.028(0.951- \\
1.111)\end{array}$ & 0.487 \\
\hline \multicolumn{7}{|l|}{ Groups } \\
\hline L & 1 (ref) & & 1 (ref) & & 1 (ref) & \\
\hline $\mathrm{H}$ & $\begin{array}{l}1.813(1.223- \\
2.687)\end{array}$ & 0.003 & $\begin{array}{l}1.495(1.028- \\
2.174)\end{array}$ & 0.035 & $\begin{array}{l}1.062(0.572- \\
1.972)\end{array}$ & 0.849 \\
\hline \multicolumn{7}{|c|}{ Data are presented as the odds ratio $(\mathrm{OR})(95 \% \mathrm{Cl})$. } \\
\hline ETB:Embryo transfer with & ogically go & ysts & & & & \\
\hline
\end{tabular}

\section{Characteristics of clinical outcomes of ETC}

The rate of fresh cycles in the $\mathrm{L}$ or $\mathrm{H}$ groups was similar (Table 4). The rate of cycles with grade I or grade I + grade II embryos was significantly higher, while the rate of grade II embryos was significantly lower in the H group than that in the L group (Table 4). More embryos per ET cycle was observed in the $\mathrm{H}$ group (Table 4). The rate of singleton, pregnancy, abortion, live birth, implantation and live birth per embryo was comparable in the $\mathrm{H}$ and $\mathrm{L}$ groups (Table 4). 
Table 4

Characteristics and clinical outcomes of ETC

\begin{tabular}{|c|c|c|c|}
\hline & $\mathrm{L}$ & $\mathrm{H}$ & $\mathbf{P}$ \\
\hline ET cycles & 259 & 189 & \\
\hline Fresh (\%) & $115(44.4)$ & 101(53.4) & 0.0587 \\
\hline Frozen (\%) & $144(55.6)$ & $88(46.6)$ & 0.0587 \\
\hline I (\%) & $7(2.7)$ & $47(24.9)$ & \\
\hline I + II (\%) & $19(7.3)$ & $61(32.3)$ & \\
\hline II (\%) & $233(90.0)$ & $81(42.9)$ & \\
\hline Number of embryos per transfer & $1.88 \pm 0.32$ & $1.98 \pm 0.14$ & 0.0002 \\
\hline Pregnant rate (\%) & $145(55.98)$ & $111(58.73)$ & 0.562 \\
\hline Abortion rate $(\%)$ & $21(14.48)$ & $14(12.61)$ & 0.666 \\
\hline Live birth rate (\%) & $124(47.88)$ & $97(51.32)$ & 0.4712 \\
\hline Implantation rate (\%) & 193/488 (39.55) & 157/374 (41.98) & 0.4716 \\
\hline Live birth per embryo (\%) & 159/488 (32.58) & $133 / 374(35.56)$ & 0.3596 \\
\hline \multicolumn{4}{|c|}{ Data are presented as the median [the first quartile, the third quartile] or count (percentage) or Mean $\pm \mathrm{S}$} \\
\hline ETC: Embryo transfer with morp & ood day 3 embry & & \\
\hline
\end{tabular}

\section{Factors affecting the clinical outcomes of ETC}

Binary logistic regression analysis showed that semen DFI and female age significantly affected clinical pregnancy and live birth (Table 5). After controlling factor including female or male age, number of embryos transferred, female BMI, semen DFI and grade of embryos, we found MG embryos from the $L$ group showed similar chance of implantation or live birth, compared to the $\mathrm{H}$ group (Table 5). 
Table 5

Association between factors and clinical outcomes in ETC

\begin{tabular}{|c|c|c|c|c|c|c|}
\hline & \multicolumn{2}{|c|}{ Clinical pregnancy } & \multicolumn{2}{|l|}{ Live birth } & \multicolumn{2}{|l|}{ abortion } \\
\hline & OR (95\% CL) & $\mathrm{p}$ & OR (95\% CL) & $\mathrm{p}$ & OR (95\% CL) & $\mathrm{p}$ \\
\hline \multicolumn{7}{|l|}{ ET cycles } \\
\hline Grade I & 1 (ref) & & 1 (ref) & & 1 (ref) & \\
\hline Grade I+ II & $\begin{array}{l}0.796(0.390- \\
1.626)\end{array}$ & 0.531 & $\begin{array}{l}0.857(0.420- \\
1.750)\end{array}$ & 0.672 & $\begin{array}{l}0.857(0.239- \\
3.069)\end{array}$ & 0.812 \\
\hline Grade II & $\begin{array}{l}1.057(0.529- \\
2.115)\end{array}$ & 0.875 & $\begin{array}{l}1.272(0.638- \\
2.536)\end{array}$ & 0.494 & $\begin{array}{l}0.521(0.154- \\
1.757)\end{array}$ & 0.293 \\
\hline $\begin{array}{l}\text { Number of embryos } \\
\text { transferred }\end{array}$ & $\begin{array}{l}1.706(0.806- \\
3.610)\end{array}$ & 0.162 & $\begin{array}{l}1.576(0.734- \\
3.385)\end{array}$ & 0.244 & $\begin{array}{l}1.112(0.218- \\
5.767)\end{array}$ & 0.899 \\
\hline Semen DFI & $\begin{array}{l}1.031(1.001- \\
1.063)\end{array}$ & 0.046 & $\begin{array}{l}1.034(1.003- \\
1.065)\end{array}$ & 0.029 & $\begin{array}{l}0.973(0.919- \\
1.030)\end{array}$ & 0.347 \\
\hline Female BMI & $\begin{array}{l}1.002(0.986- \\
1.019)\end{array}$ & 0.784 & $\begin{array}{l}0.990(0.967- \\
1.013)\end{array}$ & 0.395 & $\begin{array}{l}1.027(0.984- \\
1.071)\end{array}$ & 0.219 \\
\hline Female age & $\begin{array}{l}0.891(0.830- \\
0.957)\end{array}$ & 0.002 & $\begin{array}{l}0.885(0.823- \\
0.951)\end{array}$ & 0.001 & $\begin{array}{l}1.145(0.980- \\
1.338)\end{array}$ & 0.089 \\
\hline Male age & $\begin{array}{l}1.008(0.956- \\
1.063)\end{array}$ & 0.760 & $\begin{array}{l}1.012(0.960- \\
1.067)\end{array}$ & 0.668 & $\begin{array}{l}0.970(0.868- \\
1.084)\end{array}$ & 0.588 \\
\hline \multicolumn{7}{|l|}{ Groups } \\
\hline L & 1 (ref) & & 1 (ref) & & 1 (ref) & \\
\hline $\mathrm{H}$ & $\begin{array}{l}1.204(0.737- \\
1.968)\end{array}$ & 0.458 & $\begin{array}{l}1.345(0.826- \\
2.190)\end{array}$ & 0.233 & $\begin{array}{l}0.629(0.252- \\
1.568))\end{array}$ & 0.320 \\
\hline \multicolumn{7}{|c|}{ Data are presented as the odds ratio (OR) $(95 \% \mathrm{Cl})$. } \\
\hline ETC:Embryo transfer & ologically go & ye em & os & & & \\
\hline
\end{tabular}

\section{Discussion}

In the present study, we found that transfer of MG day 3 cleavage embryos in patients with low RMD3 had similar clinical outcomes as transfer of MG day 3 embryos in patients with high RMD3. However, if seeking blastocysts-stage transfer, the usable blastocyst formation rate from MG day 3 embryos, implantation rate and live birth rate from transfer of MG blastocyts were significantly reduced in patients with low RMD3 as compared to patients with high RMD3.

Previous studies showed that patients with number of good quality embryos ( $>3$ ) on day 3 indicated good prognosis, and blastocyst transfer was suggested for those patients $(20,21)$. Different from those studies, in the present study, we grouped the patients/cycles by RMD3.This definition focused on the formative capacity of overall MG embryos on day 3 rather than the absolute counts. It is known that the follicles within ovary promoted by controlled ovarian stimulation share a common growth environment and genetic foundation. High RMD3 may reflect good maturation of oocytes and ovarian condition, while low RMD3 may reflect weak maturation of oocytes and ovarian function. However, whether the remaining MG embryos from low RMD3 show similar quality with MG embryos from high RMD3 remains elusive Due to fresh cycles with 2PN zygotes $=>5$ in the present study, the patients included in the present study were at least normal responders.

In the present, patients with ETC and ETB represented distinct population. This was due to the laboratory strategy. In our reproductive center, around 2 best quality of MG day 3 embryos will be frozen or transferred, and the remaining will be further cultured. For embryo transfer, MG blastocysts have the highest priority, followed by MG day 3 embryos. Therefore, patients 
having frozen ETC may indicate no available MG blastocysts, and about half of patients having fresh ETC resulted in live birth in the present study. We noticed that patients having ETB showed higher ovarian reserve and response, less $\mathrm{Gn}$ use and more oocytes retrieved, and higher usable blastocysts formation rate (from MG or MNG day 3 embryos) in the L or $\mathrm{H}$ group, compared to patients having ETC. This was reasonable. Because, with similar RMD3, patients with more number of eggs and high rate of blastocyst formation mean more chance of having MG blastocysts. It has been reported that more dose of Gn use adversely affect the quality of eggs $(22,23)$. By contrast, a recent study showed that poor responders with less Gn use may result in better oocyte quality(24). Therefore, it was possible that less $\mathrm{Gn}$ dose may be associated with better performance of patients in ETB group.

The baseline characteristics of patients and consequent ovulation protocols were grossly comparable between the $L$ and $H$ groups in patients with ETB or ETC .For ETC, patients in the H group showed relatively low response to Gn, evidenced by similar Gn use and reduced oocytes retrieved compared to the $L$ group. However, the reduced oocytes retrieved were compensated by high RMD3, resulting in more available MG embryos on day 3 and subsequent more MG day 3 embryos for expended culture in the $\mathrm{H}$ group. For ETB, patients in the $\mathrm{H}$ group showed similar $\mathrm{Gn}$ use and oocytes retrieved, compared to patients in the $\mathrm{L}$ group. Furthermore, we observed that normal fertilization rate was significantly higher in the H group than the L group in either ETC or ETB group. Therefore, grouping by RMD3 didn't introduce obvious confounding factors regarding baseline characteristics of patients and cycles.

Blastulation rate is also an important indicator reflecting embryo quality. Useable blastocyst formation rate (from MG day 3 embryos) was significantly reduced in the $L$ group in either ETC or ETB group. However, useable blastocyst formation rate from MNG day 3 embryos were similar in the $L$ and $H$ groups in either ETC or ETB group. Due to limited cases of MNG day 3 embryos for further culture in the $\mathrm{H}$ group, this observation need large data to confirm. In addition, the difference in useable blastocyst formation rate between the $\mathrm{H}$ and $\mathrm{L}$ groups is bigger in ETC group than that in ETB group. We proposed that over all good performance of patients in ETB group may partially shorten the difference in usable blastocysts formation rate between the $\mathrm{H}$ and L groups. In conclusion, MG day 3 embryos from patients with low RMD3 showed decreased in vitro developmental potential (DP).

The golden maker reflecting the quality of embryo is whether the embryo can result in a live birth (25). For ETB, we found that not only clinical pregnancy rate and live birth rate, but also implantation rate and livebirth rate per embryo were significantly higher in the $\mathrm{H}$ group than the $\mathrm{L}$ group. It is know that female age and BMI, number of embryos transferred and semen DFI and days of blastocysts may have profound influences on the clinical outcomes of in vitro fertilization (25-31). Conflicting results were reported regarding the effect of male age on the clinical outcomes of in vitro fertilization $(32,33)$. However, in the present study, we found that there was a trend towards decreased male age in the $\mathrm{H}$ group, compared to the $\mathrm{L}$ group. Therefore, the male age was also taken as a potential confounding factor. As expected, we showed that number of embryos transferred positively while female age adversely affected clinical pregnancy and live birth, indicating the confidence of our data. In line with a recent study (34), transfer of day 6 blastocysts increase the risk of abortion than transfer of day 5 blastocysts. After controlling factors including female or male age, number of embryos transferred, female BMI, semen DFI and days of blastocyst, we found MG blastocysts from the L group showed decreased chance of implantation or live birth, compared to MG blastocysts from the $\mathrm{H}$ group. Therefore, the in vivo DP of MG blastocysts was reduced significantly in patients with low RMD3, compared to patients with high RMD3.

To our surprise, we found that although more ET cycles with grade I or grade I + grade II embryos in the H group, transfer of MG day 3 embryos resulted in similar clinical pregnancy rate, live birth rate, implantation rate per embryo and live birth rate per embryo between the $\mathrm{H}$ and $\mathrm{L}$ groups. Further analysis showed that semen DFI positively and minimally affected the clinical pregnancy and live birth. This result was inconsistent with previous findings(31, 35). However, DFI of males in the present study was low, it was possible that a higher of DFI (under certain threshold) may minimally benefit patients with transfer of MG day 3 embryos. Consistent with previous studies $(36,37)$, we observed that female age adversely affected clinical pregnancy and live birth. In addition, grade I embryos did not result in better clinical outcomes as compared to grade II embryos. After controlling factors including female or male age, number of embryos transferred, female BMI, semen DFI and grade of embryos, we found 
MG embryos from the $L$ group showed similar chance of implantation or live birth, compared to the $H$ group. Therefore, the in vivo DP of MG day 3 embryos was similar in patients with high and low RTD3.

A low in vitro DP and similar in vivo DP of MG day 3 embryos were observed in the $L$ group, compared to the $H$ group. It has been proposed that day 3 embryos which fails to develop into blastocysts in vitro may lead to live births in vivo (38). One reasonable explanation was that MG day 3 embryos from patients with low RMD3 is sensitive to in vitro culture but not to in vivo environment, compared to MG day 3 embryos from patients with high RMD3.

Patients with low RMD3 may experience satisfying 2PN zygotes and limited number of MG day 3 embryos. Our study showed that a single transfer cycle of MG day 3 embryos for patients with low RMD3 had similar clinical outcomes as compared to a single transfer cycle of MG day 3 embryos for patients with high RMD3. However, if seeking blastocysts-stage transfer, the usable blastocysts formation rate from MG day 3 embryos, implantation rate and live birth rate from transfer of MG blastocyts were significantly reduced in patients with low RMD3 as compared to patients with high RMD3. According to our study, we suggested that for patients with low RMD3, it seems that transfer of MG day 3 embryos may benefit patients. This strategy my potentially avoid the possible wastage of MG day 3 embryos during in vitro culture and the possible wastage of MG blastocysts during implantation.

The main limitation of this study is its nature of the retrospective study. Patients with ETB and ETC represented relatively separate population in either the $\mathrm{L}$ group or the $\mathrm{H}$ group. A concern is whether it was appropriate that results from separate populations were integrated for analysis. This study was a comparison study and did not provide the direct evidence.

Furthermore, the data included for analysis were from single center and the cases included in the present study is limited, therefore, the indications from this study still need to be confirmed by large randomized control trial.

\section{Conclusion}

The in vitro DP of MG day 3 embryos and in vivo DP of MG blastocysts were reduced significantly, while a similar in vivo DP of MG day 3 embryos was observed in patients with low RMD3 as compared to patients with high RMD3. It seems that direct transfer of day 3 MG embryos instead of extended culture may benefit patients with RMD3.

\section{Declarations}

\section{Acknowledgments}

Not applicable

\section{Author contributions}

Substantial contribution to conception and design: L.C., X.D. and Y.W. ; Data acquisition: X.X., T.G. F.C; Data analysis: X.X., T.G.,C.Y.,F.C., T.L. and L.L; Data interpretation: all authors. Drafting the article: X.D. and Y.W. ;Critical revision of the article for important intellectual content: all authors. Final approval of the article: all authors.

\section{Funding}

This study was supported by the National Natural Science Foundation of China (No.81901436, to X.D), Changzhou Health Committee Funded Young Investigator Training Project (CZQM2020094 to X.D.\& CZQM2020099 to T.G.), Key Program of Changzhou Municipal Health Commission (ZD201921 to L.C.), Program of Jiangsu Province's Key Provincial Talents of Women and Child Health Care (FRC 201751 to L.C.) and Jiangsu Population Institute funded program (JSPA2019017 to T.L.).

\section{Conflict of Interest:}

The authors declare that they have no conflict of interest.

\section{Availability of data and materials}

Page 13/17 
The datasets used and/or analysed during the current study are available from the corresponding author on reasonable request.

\section{Ethics approval}

\section{Ethics approval and consent to participate}

This retrospective study was approved by the Ethics Committee of Changzhou Maternal and Child Health Care Hospital and Nanjing Medical University. All the treatments in the present study were performed strictly in accordance with the Declaration of Helsinki for Medical Research.

The study doesn't contain any data from an individual person.

\section{Competing interests}

The authors declare that they have no competing interests.

All authors read and approved the final manuscript.

\section{References}

1. van Loendersloot LL, van Wely M, Limpens J, Bossuyt PM, Repping S, van der Veen F. Predictive factors in in vitro fertilization (IVF): a systematic review and meta-analysis. Hum Reprod Update. 2010;16(6):577-89. doi:10.1093/humupd/dmq015.

2. Drakopoulos P, Errazuriz J, Santos-Ribeiro S, Tournaye H, Vaiarelli A, Pluchino N, et al. Cumulative live birth rates in in-vitro fertilization. Minerva Ginecol. 2019;71(3):207-10. doi:10.23736/S0026-4784.18.04347-2.

3. Polyzos NP, Drakopoulos P, Parra J, Pellicer A, Santos-Ribeiro S, Tournaye H, et al. Cumulative live birth rates according to the number of oocytes retrieved after the first ovarian stimulation for in vitro fertilization/intracytoplasmic sperm injection: a multicenter multinational analysis including approximately 15,000 women. Fertil Steril. 2018;110(4):661 - 70 e1. doi:10.1016/j.fertnstert.2018.04.039.

4. Sunkara SK, Rittenberg V, Raine-Fenning N, Bhattacharya S, Zamora J, Coomarasamy A. Association between the number of eggs and live birth in IVF treatment: an analysis of 400135 treatment cycles. Hum Reprod. 2011;26(7):1768-74. doi:10.1093/humrep/der106.

5. Ji J, Liu Y, Tong XH, Luo L, Ma J, Chen Z. The optimum number of oocytes in IVF treatment: an analysis of 2455 cycles in China. Hum Reprod. 2013;28(10):2728-34. doi:10.1093/humrep/det303.

6. Machtinger R, Racowsky C. Morphological systems of human embryo assessment and clinical evidence. Reprod Biomed Online. 2013;26(3):210-21. doi:10.1016/j.rbmo.2012.10.021.

7. Takeuchi K. Pre-implantation genetic testing: Past, present, future. Reprod Med Biol. 2021;20(1):27-40. doi:10.1002/rmb2.12352.

8. Zaninovic N, Rosenwaks Z. Artificial intelligence in human in vitro fertilization and embryology. Fertil Steril. 2020;114(5):914-20. doi:10.1016/j.fertnstert.2020.09.157.

9. Xu J, Fang R, Chen L, Chen D, Xiao JP, Yang W, et al. Noninvasive chromosome screening of human embryos by genome sequencing of embryo culture medium for in vitro fertilization. Proc Natl Acad Sci U S A. 2016;113(42):11907-12. doi:10.1073/pnas.1613294113.

10. Boediono A, Handayani N, Sari HN, Yusup N, Indrasari W, Polim AA, et al. Morphokinetics of embryos after IMSI versus ICSI in couples with sub-optimal sperm quality: A time-lapse study. Andrologia. 2021;53(4):e14002. doi:10.1111/and.14002.

11. Lou H, Li N, Guan Y, Zhang Y, Hao D, Cui S. Association between morphologic grading and implantation rate of Euploid blastocyst. J Ovarian Res. 2021;14(1):18. doi:10.1186/s13048-021-00770-8.

12. Van Royen E, Mangelschots K, De Neubourg D, Valkenburg M, Van de Meerssche M, Ryckaert G, et al. Characterization of a top quality embryo, a step towards single-embryo transfer. Hum Reprod. 1999;14(9):2345-9. 
doi:10.1093/humrep/14.9.2345.

13. Bar-Hava I, Ferber A, Ashkenazi J, Orvieto R, Kaplan B, Bar J, et al. Does female age affect embryo morphology? Gynecol Endocrinol. 1999;13(6):371-4. doi:10.3109/09513599909167582.

14. Dai X, Wang Y, Yang H, Gao T, Yu C, Cao F, et al. AMH has no role in predicting oocyte quality in women with advanced age undergoing IVF/ICSI cycles. Sci Rep. 2020;10(1):19750. doi:10.1038/s41598-020-76543-y.

15. Lee TH, Chen CD, Tsai YY, Chang LJ, Ho HN, Yang YS. Embryo quality is more important for younger women whereas age is more important for older women with regard to in vitro fertilization outcome and multiple pregnancy. Fertil Steril. 2006;86(1):64-9. doi:10.1016/j.fertnstert.2005.11.074.

16. Morin SJ, Patounakis G, Juneau CR, Neal SA, Scott RT, Seli E. Diminished ovarian reserve and poor response to stimulation in patients < 38 years old: a quantitative but not qualitative reduction in performance. Hum Reprod. 2018;33(8):1489-98. doi:10.1093/humrep/dey238.

17. Oron G, Son WY, Buckett W, Tulandi T, Holzer H. The association between embryo quality and perinatal outcome of singletons born after single embryo transfers: a pilot study. Hum Reprod. 2014;29(7):1444-51. doi:10.1093/humrep/deu079.

18. Li J, Chen Q, Wang J, Huang G, Ye H. Does growth hormone supplementation improve oocyte competence and IVF outcomes in patients with poor embryonic development? A randomized controlled trial. BMC Pregnancy Childbirth. 2020;20(1):310. doi:10.1186/s12884-020-03004-9.

19. Bungum $M$, Bungum L, Humaidan P. A prospective study, using sibling oocytes, examining the effect of 30 seconds versus 90 minutes gamete co-incubation in IVF. Hum Reprod. 2006;21(2):518-23. doi:10.1093/humrep/dei350.

20. Volpes A, Sammartano F, Coffaro F, Mistretta V, Scaglione P, Allegra A. Number of good quality embryos on day 3 is predictive for both pregnancy and implantation rates in in vitro fertilization/intracytoplasmic sperm injection cycles. Fertil Steril. 2004;82(5):1330-6. doi:10.1016/j.fertnstert.2004.03.067.

21. Papanikolaou EG, D'Haeseleer E, Verheyen G, Van de Velde H, Camus M, Van Steirteghem A, et al. Live birth rate is significantly higher after blastocyst transfer than after cleavage-stage embryo transfer when at least four embryos are available on day 3 of embryo culture. A randomized prospective study. Hum Reprod. 2005;20(11):3198-203. doi:10.1093/humrep/dei217.

22. Santos MA, Kuijk EW, Macklon NS. The impact of ovarian stimulation for IVF on the developing embryo. Reproduction. 2010;139(1):23-34. doi:10.1530/REP-09-0187.

23. Roberts R, latropoulou A, Ciantar D, Stark J, Becker DL, Franks S, et al. Follicle-stimulating hormone affects metaphase I chromosome alignment and increases aneuploidy in mouse oocytes matured in vitro. Biol Reprod. 2005;72(1):107-18. doi:10.1095/biolreprod.104.032003.

24. Moffat R, Hansali C, Schoetzau A, Ahler A, Gobrecht U, Beutler S, et al. Randomised controlled trial on the effect of clomiphene citrate and gonadotropin dose on ovarian response markers and IVF outcomes in poor responders. Hum Reprod. 2021;36(4):987-97. doi:10.1093/humrep/deaa336.

25. Ata B, Seyhan A, Seli E. Diminished ovarian reserve versus ovarian aging: overlaps and differences. Curr Opin Obstet Gynecol. 2019;31(3):139-47. doi:10.1097/GC0.0000000000000536.

26. Zhang JJ, Liu X, Chen L, Zhang S, Zhang X, Hao C, et al. Advanced maternal age alters expression of maternal effect genes that are essential for human oocyte quality. Aging (Albany NY). 2020;12(4):3950-61. doi:10.18632/aging.102864.

27. Sermondade N, Huberlant S, Bourhis-Lefebvre V, Arbo E, Gallot V, Colombani M, et al. Female obesity is negatively associated with live birth rate following IVF: a systematic review and meta-analysis. Hum Reprod Update. 2019;25(4):43951. doi:10.1093/humupd/dmz011.

28. Kasum M, Oreskovic S, Cehic E, Lila A, Ejubovic E, Soldo D. The role of female obesity on in vitro fertilization outcomes. Gynecol Endocrinol. 2018;34(3):184-8. doi:10.1080/09513590.2017.1391209.

29. Pandian Z, Marjoribanks J, Ozturk O, Serour G, Bhattacharya S. Number of embryos for transfer following in vitro fertilisation or intra-cytoplasmic sperm injection. Cochrane Database Syst Rev 2013; (7):CD003416. doi:10.1002/14651858.CD003416.pub4.

Page 15/17 
30. Oleszczuk K, Giwercman A, Bungum M. Sperm chromatin structure assay in prediction of in vitro fertilization outcome. Andrology. 2016;4(2):290-6. doi:10.1111/andr.12153.

31. Micinski P, Pawlicki K, Wielgus E, Bochenek M, Tworkowska I. The sperm chromatin structure assay (SCSA) as prognostic factor in IVF/ICSI program. Reprod Biol. 2009;9(1):65-70. doi:10.1016/s1642-431x(12)60095-3.

32. Mariappen U, Keane KN, Hinchliffe PM, Dhaliwal SS, Yovich JL. Neither male age nor semen parameters influence clinical pregnancy or live birth outcomes from IVF. Reprod Biol. 2018;18(4):324-9. doi:10.1016/j.repbio.2018.11.003.

33. Van Opstal J, Fieuws S, Spiessens C, Soubry A. Male age interferes with embryo growth in IVF treatment. Hum Reprod. 2021;36(1):107-15. doi:10.1093/humrep/deaa256.

34. Shi D, Xu J, Zhang M, Niu W, Shi H, Yao G, et al. Association between the quality of inner cell mass and first trimester miscarriage after single blastocyst transfer. Reprod Biol Endocrinol. 2020;18(1):43. doi:10.1186/s12958-020-00595-y.

35. Zini A, Boman JM, Belzile E, Ciampi A. Sperm DNA damage is associated with an increased risk of pregnancy loss after IVF and ICSI: systematic review and meta-analysis. Hum Reprod. 2008;23(12):2663-8. doi:10.1093/humrep/den321.

36. Gleicher N, Kushnir VA, Albertini DF, Barad DH. Improvements in IVF in women of advanced age. J Endocrinol. 2016;230(1):F1-6. doi:10.1530/JOE-16-0105.

37. Yan J, Wu K, Tang R, Ding L, Chen ZJ. Effect of maternal age on the outcomes of in vitro fertilization and embryo transfer (IVF-ET). Sci China Life Sci. 2012;55(8):694-8. doi:10.1007/s11427-012-4357-0.

38. Gleicher N, Kushnir VA, Barad DH. Is it time for a paradigm shift in understanding embryo selection? Reprod Biol Endocrinol. 2015;13:3. doi:10.1186/1477-7827-13-3.

\section{Figures}

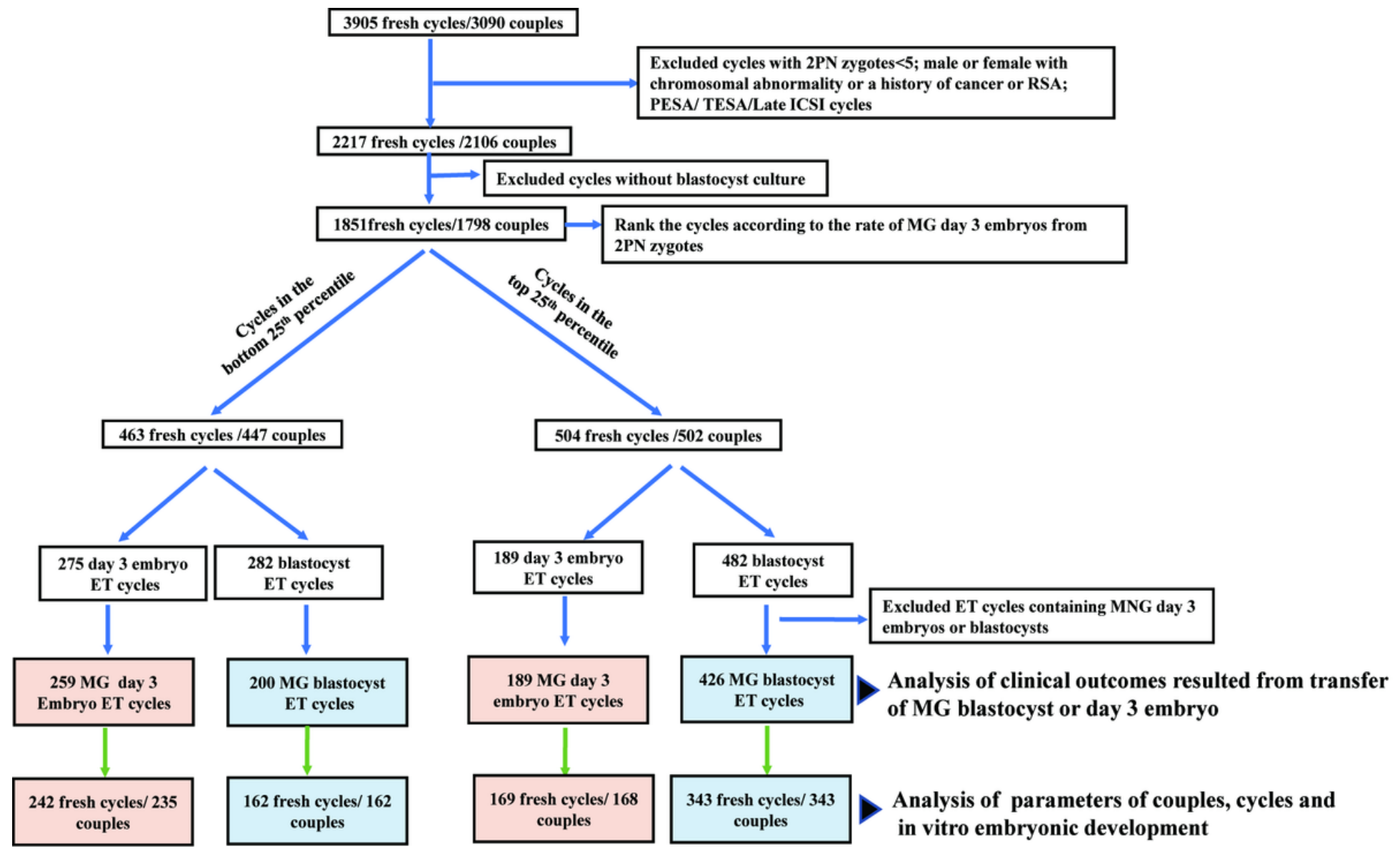

Figure 1 
The flow chart of the present study. Following the exclusion of cycles with $2 \mathrm{PN}$ zygotes $<5$, or without blastocyst culture, male or female with a history of cancer or chromosomal abnormality, or female having a diagnosis of recurrent spontaneous abortion, a total of 1851 fresh cycles was left for analysis. Cycles were ranked by RMD3. The cycles in the bottom 25th percentile were defined as the $\mathrm{L}$ group, while the cycles in the top 25th were defined as the $\mathrm{H}$ group. The data from 463 fresh cycles in the $\mathrm{L}$ group and 504 fresh cycles in the $\mathrm{H}$ group contributed ET cycles was included .After the exclusion of ET cycles with MNG embryos, data from ET cycles in the $\mathrm{L}$ group and $\mathrm{H}$ groups were collected for analysis of clinical outcomes. ET cycles related fresh cycles were collected to analyze the parameters of couples, cycles and in vitro embryonic development.
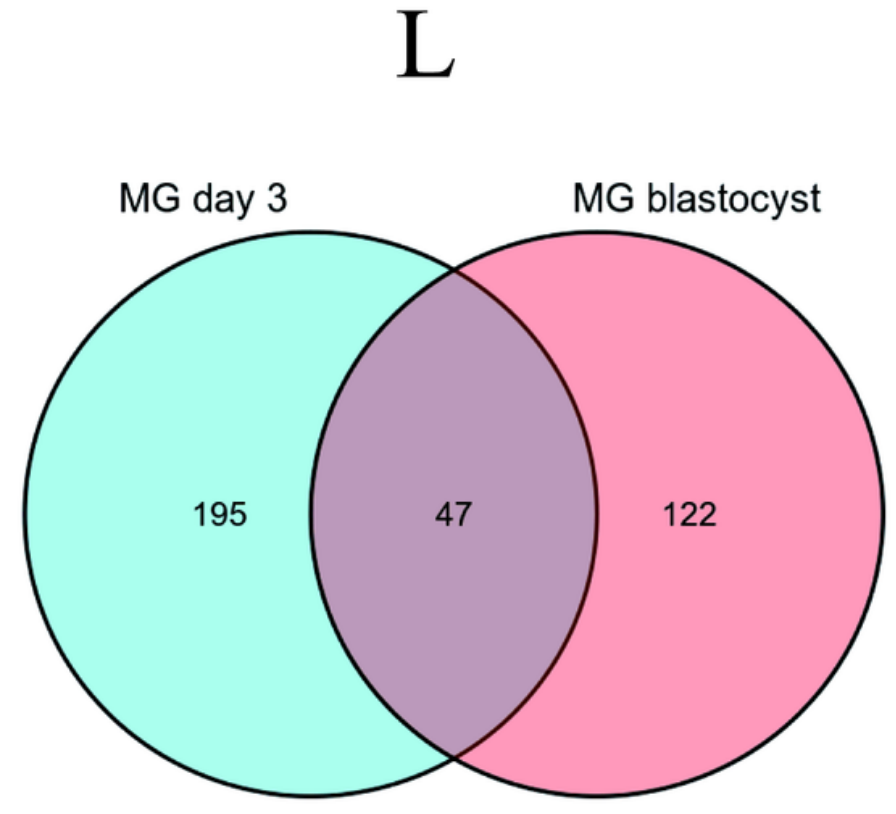

$\mathrm{H}$

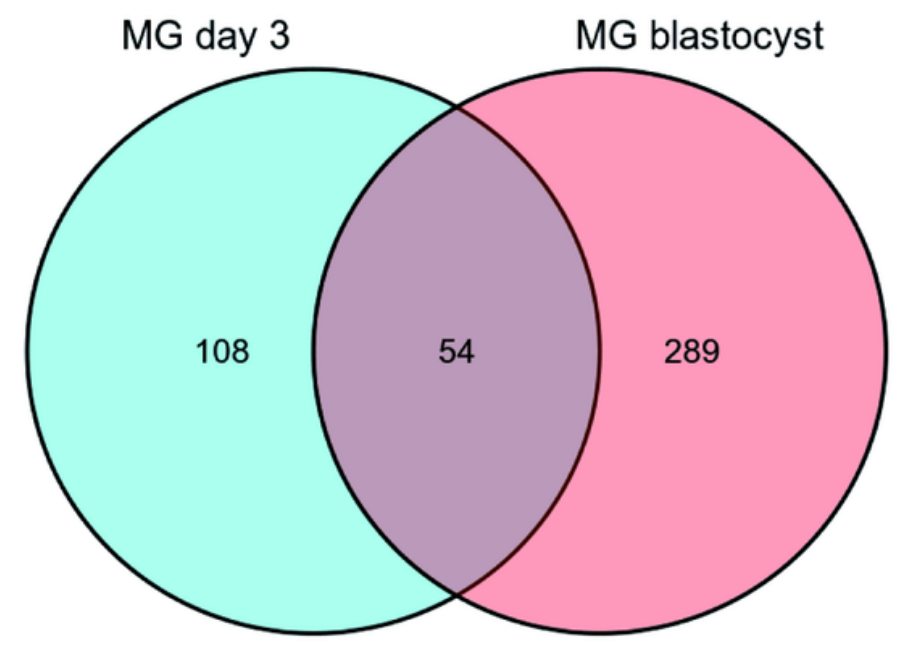

\section{Figure 2}

Fresh cycles with only MG day 3 embryo transfer, with only MG blastocyst transfer, with both MG day 3 embryo and blastocyst transfer in the L or H group. 195vs. 108 fresh cycles contributed only MG day 3 embryo transfer, 122 vs.289 fresh cycles contributed only MG blastocyst transfer and 47 vs. 54 fresh cycles contributed both MG day 3 embryo and blastocyst transfer in the L vs. H group. 